\title{
Lateral Asymmetries and Thalamic Components in Far-Field Somatosensory Evoked Potentials
}

\author{
M.J. Taylor and S.E. Black
}

\begin{abstract}
To investigate the neural generators of the subcortical somatosensory evoked potential (SEP) waves we studied the far-field SEPs in 20 normal adults. We stimulated the median nerve at the wrist and used a 40k gain, $25 \mathrm{msec}$ sweep and a $150-3000 \mathrm{~Hz}$ bandpass. We recorded SEPs simultaneously over $\mathrm{C3}^{\prime}$ and $\mathrm{C4}^{\prime}$ using a non-cephalic clavicle reference. The following series of six positive waves were found reliably in all subjects: P9, P11, P13, P14, P16 and P17.

The P16 and P17 probably arise from the thalamus and/or thalamocortical projections. Recent evidence suggests that the thalamus is not a closed field and thus one should be able to find corresponding waveforms in far-field recordings. We believe that this is a function of the bandpass used and with the above paradigm these components can be reliably recorded.

We found significant ipsilateral and contralateral amplitude asymmetries beginning with the negative deflection after P14 and including P16 and P17. The amplitude was greater over the contralateral hemisphere. This suggested that both P13 and P14 are generated prior to decussation of the afferent fibres in the medial lemniscus. Bilateral recording allowed detection of this asymmetry which has not been previously reported as a means of determining the electrophysiological correlates of lateralization.
\end{abstract}

RÉSUMÉ: Afin d'étudier les générateurs neuronaux des potentiels évoqués somato sensitifs sous-corticaux nous avons analysé les SEPs chez 20 adultes normaux (nerf médian au poignet; $40 \mathrm{~K}$ de gain, $25 \mathrm{~m}$ sec et $150-3000 \mathrm{~Hz}$ ). Nous avons enregistré simultanément les SEPs à C3' et C4', nous servant d'une référence non céphalique à la clavicule. Nous avons toujours retrouvé les ondes positives suivantes: $\mathrm{P}_{9}, \mathrm{P}_{11}, \mathrm{P}_{13}, \mathrm{P}_{14}, \mathrm{P}_{16}, \mathrm{P}_{17}$.

Les ondes $\mathrm{P}_{16}$ et $\mathrm{P}_{17}$ originent probablement du thalamus et/ou des projections thalamo-corticales. L'expérience récente indique que le thalamus n'est pas un champ clos et qu'ainsi nous devrions retrouver des ondes correspondantes en enregistrant à distance. Nous croyons avoir réussi avec les coordonnées mentionnées ci-haut.

Nous avons souvent retrouvé des asymétries d'amplitude ipsi et contralatérales, particulièrement une déviation négative après $P_{14}$ et souvent $P_{16}$ et $P_{17}$. L'amplitude était plus grande sur l'hémisphère contralatéral. Donc $P_{13}$ et $P_{14}$ pourraient être générés avant la décussation dans le lemniscus médian. L'emploi d'enregistrements bilatéraux nous a permis de découvrir cette asymétrie.

Can. J. Neurol. Sci. 1984; 11:252-256

Recently there has been a number of reports on far-field subcortical somatosensory evoked potentials (SEPs) with considerable discussion about the generators of these early waves (King and Green, 1979; Allison et al., 1980; Kritchevsky and Wierholt, 1978; Desmedt and Cheron, 1980; Jones, 1977; Anziska and Cracco, 1980). On stimulating the median nerve at the wrist and recording over the contralateral motor strip with a noncephalic reference, a series of small waves appear between 9 and $20 \mathrm{msec}$ after stimulation. Since their first discovery (Cracco and Cracco, 1976) researchers have become increasingly specific in their speculations about the generators of these potentials.
The general consensus now is that $\mathrm{P} 9$ arises from the brachial plexus and P11 from the cervical dorsal columns. P13 and P14 are thought to be generated in the cuneate nucleus and the medial lemniscus, respectively (Anziska and Cracco, 1981; Desmedt and Cheron, $1980 ; 1981$ ), and the large wave at 20 msec is the primary cortical response.

Only a few investigators have found replicable waves in the 6 msec between P14 and N20. Desmedt and Cheron (1981) reported inflections on the rising limb of $\mathrm{N} 20$, the most consistent of which they labelled N18, and attributed to thalamic activity. These were not seen in all subjects and were often very small.

From the Division of Neurology, Departments of Paediatrics and Medicine, University of Toronto, The Hospital for Sick Children, Toronto, Canada

Received September 6, 1983. Accepted January 14, 1984

Reprint requests to: Dr. M.J. Taylor, Division of Neurology, Hospital for Sick Children, 555 University Avenue, Toronto, Ontario, Canada M5G 1 X8 
Abbruzzese et al. (1978) and Eisen (1982) using an Fz reference reported two intervening waves, N16 and N17, which they felt arose from the thalamus and thalamocortical radiations. Maccabee et al. (1983) using a restricted bandpass of $300-3000 \mathrm{~Hz}$ reported a series of waves, N16, P17, N18 and P19, which they also suggested arose from the thalamus and its cortical projections.

In order to further elucidate these subcortical components we studied the far-field SEPs in normal adults, using a noncephalic reference and a restricted bandpass of $150-3000 \mathrm{~Hz}$. In this study we describe two clear, positive components that occur at 16 and $17 \mathrm{msec}$, and we present lateralization data that allow new inferences about the localization of P13 and P14.

\section{Methods}

Twenty normal adults ( 13 female) ranging in age from 21-39 years (mean 29 years) were studied. Subjects lay comfortably on a bed during the recording session and many fell asleep. The SEPs were recorded over both right and left sensory motor strips ( $\mathrm{C}^{\prime}$ and $\mathrm{C} 4^{\prime}, 2 \mathrm{~cm}$ posterior to $\mathrm{C} 3$ and $\mathrm{C} 4$ ) referenced to the midpoint of the clavicle contralateral to stimulation. Square wave pulses $200 \mu \mathrm{sec}$ in duration were applied over the median nerve just above the wrist at a rate of $4.1 / \mathrm{sec}$. Stimulation was gradually increased until a small thumb movement was elicited and the studies were then run at that intensity (range 3.3-8.0 $\mathrm{mA}$ ). The motor threshold was determined separately for right and left median nerve stimulation.

The SEPs were recorded using gold cup electrodes attached with paste and gauze; electrode impedance was always below $3 \mathrm{kOhms}$. A 40k gain and a $25 \mathrm{msec}$ sweep were used. The high and low pass filters were set at 150 and $3000 \mathrm{~Hz}(-3 \mathrm{~dB})$, respectively. Two averages of 2048 trials were obtained from each arm. Studies were also conducted in four of the subjects using an $\mathrm{Fz}$ reference but otherwise identical procedures.

The latencies of all positive peaks were measured after the data had been standardized for arm length. This was done by dividing each subject's data by the ratio of his/her arm length to the mean arm length (from wrist to $\mathrm{C7}$ ) of all subjects (mean arm length was $74 \mathrm{~cm}$ ). This reduced the variability in latencies due to individual differences in arm length. The peak amplitudes were submitted to repeated measures analysis of variance.

\section{ReSULts}

Far-field SEPs were recorded in all subjects, the waveforms consisting of the following series of seven positive peaks (upward deflection at G1): P9, P11, P13, P14, P16, P17 and P20. These peaks were distinguishable in all subjects although the morphology was variable (figure 1). The variability in the peak and interpeak latencies was comparable to that found in auditory brainstem responses (ABRs) (Table 1); when standardized for arm length the variability was less than $4 \%$ for all components. The later components were more clearly seen in the contralateral leads (figure 2). There were significant amplitude differences in the subcortical waves between ipsilateral and contralateral recordings $(F(1,38)=43.09, p<.001)$ and a significant peak by hemisphere interaction $(F(5,190)=7.51, p<.001)$ (Table 2). There was no significant difference in the ipsilateral and contralateral amplitudes of P13 and P14. The amplitude asymmetry occurred only with the negative deflection following P14 and including

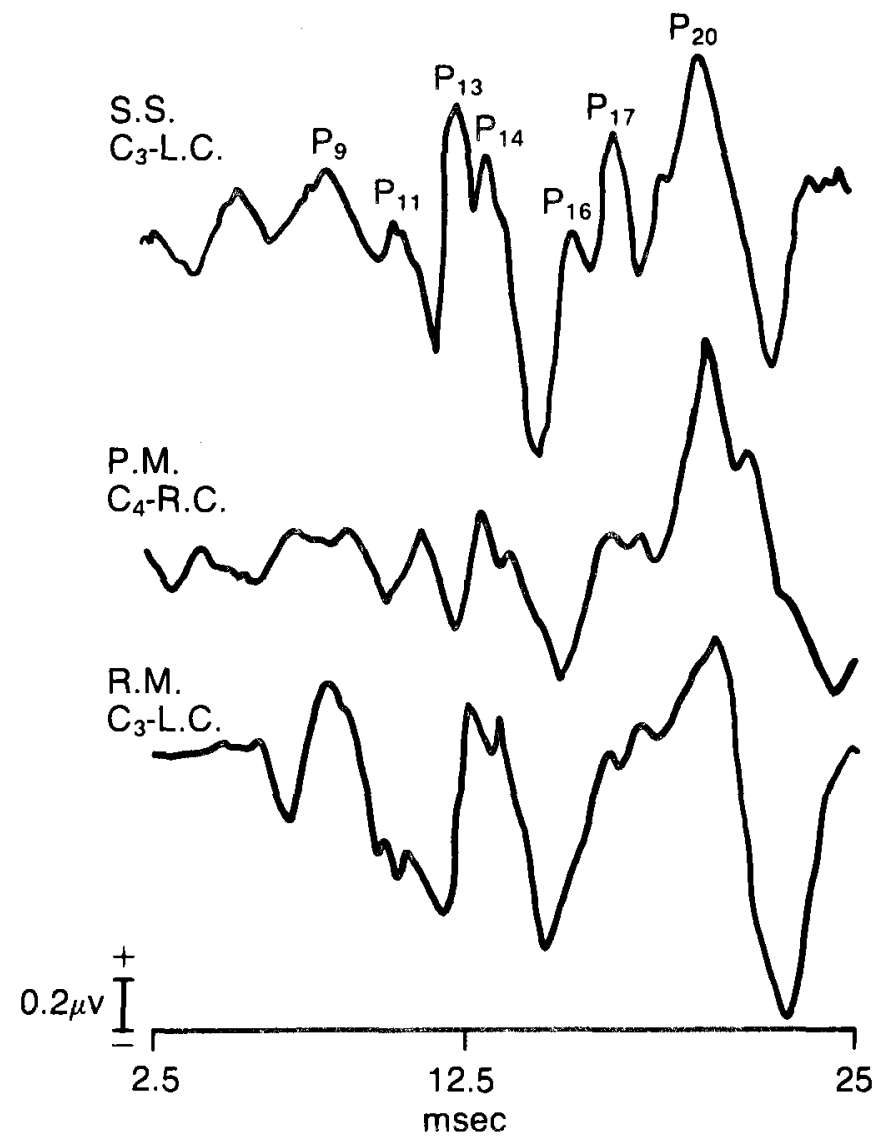

Figure 1 -Far-field SEPs from three subjects showing morphological differences. The active electrodes is at $\mathrm{C} 3$ or $\mathrm{C} 4$, referenced to either left or right clavicle.

Table 1: Mean latencies (in msec) of far-field SEP components standardized for arm length

\begin{tabular}{lccccccc}
\hline & P9 & P11 & P13 & P14 & P16 & P17 & P20 \\
\hline Mean & 8.5 & 10.8 & 12.6 & 13.8 & 16.4 & 17.6 & 20.0 \\
s.d. & .41 & .37 & .34 & .42 & .38 & .34 & .64 \\
\hline \multicolumn{7}{c}{ Mean interpeak latencies (in msec) } \\
& P9-P11 & P11-P13 & P13-P14 & P14-P16 & P16-P17 & P17.P20 \\
\hline Mean & 2.26 & 1.86 & 1.20 & 2.62 & 1.25 & 2.44 \\
s.d. & .38 & .34 & .36 & .53 & .31 & .51 \\
\hline
\end{tabular}

Table 2: Mean amplitudes (in $\mu \mathrm{V}$ ) of far-field SEP components

\begin{tabular}{lcccc}
\hline \hline & \multicolumn{2}{c}{ Ipsilateral } & \multicolumn{2}{c}{ Contralateral } \\
& mean & s.d. & mean & s.d. \\
\hline P13+ & 2.66 & 1.16 & 2.88 & 1.27 \\
P13- & 1.77 & 1.26 & 1.83 & 0.53 \\
P14+ & 0.54 & 0.53 & 0.58 & 0.55 \\
P14- & 2.28 & 1.64 & $3.11^{*}$ & 1.69 \\
P16 & 2.49 & 1.14 & $2.90^{*}$ & 1.16 \\
P17 & 1.34 & 1.04 & $1.74^{*}$ & 1.07 \\
\hline
\end{tabular}

+ positive limb

- negative limb

$* \mathrm{p}<.001$ 
P16 and P17. The amplitude was always greater over the contralateral cortex; P16 and P17 were not found ipsilaterally in all subjects.

When an $\mathrm{Fz}$ reference was employed rather than the noncephalic clavicle reference, waves P9, P11 and PI3 were not seen and the subsequent subcortical waves were of smaller amplitude (figure 3 ).

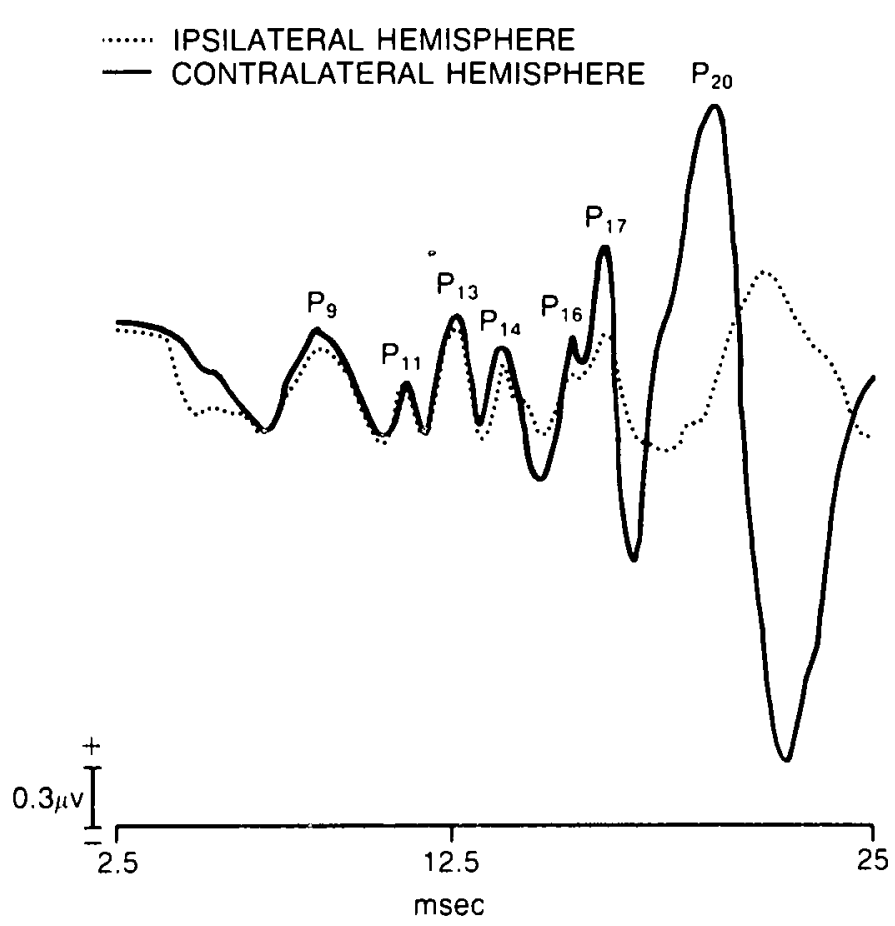

Figure 2 - Far-field SEPs recorded simultaneously over ipsilateral and contralateral hemisphere showing the hemispheric asymmetry beginning with the negative deflection after P14.

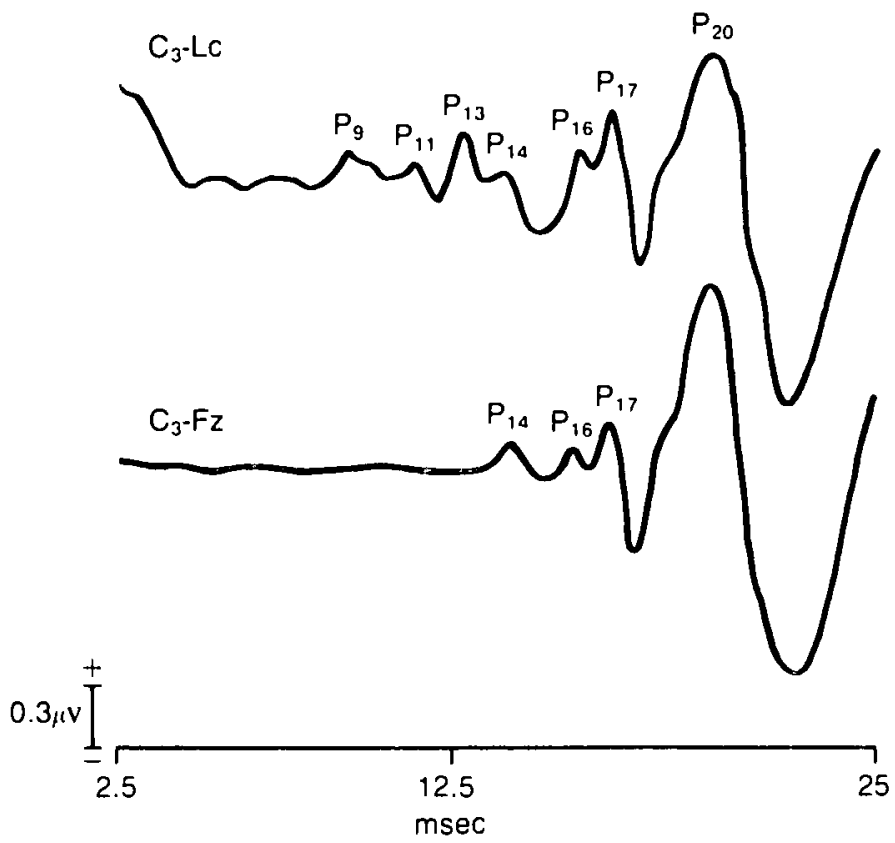

Figure 3 - Far-field SEP s recorded using a noncephalic and an F z reference, showing the loss of the earlier waves with the cephalic reference.

\section{Discussion}

By employing a non-cephalic reference and a $150-3000 \mathrm{~Hz}$ bandpass we have found a series of six positive peaks between 9 and $20 \mathrm{msec}$ following median nerve stimulation, which reflect the afferent volley passing through the subcortical somatosensory pathway. We report reliably recorded PI6 and P17 waves that are probably thalamic in origin and, also, an interhemispheric asymmetery occurring only after P14.

The waveforms are similar to those reported by Maccabee et al. (1983) using a $300-3000 \mathrm{~Hz}$ bandpass, except that their latencies of comparable components appear to be I msec longer than ours. This discrepancy might be due to longer arm length of their subjects.

We believe that the amplitude asymmetries that we found subsequent to $\mathrm{PI} 4$ contribute to our understanding of the localization of the generators of these subcortical peaks. Prior to decussation of the fibres in the medulla, one night expect that significant amplitude differences over the hemispheres would not be found. After decussation, it is possible that the far-field potentials would be larger in amplitude over the hemisphere in which they arise, if only because of the greater proximity of the recording electrode to the generators. Given this hypothesis, the lack of hemispheric asymmetry with PI3 and PI4 would suggest that both arise prior to decussation. $\mathrm{P} 13$ may arise from the afferent volley arriving at the cuneate nucleus and PI4 from the volley passing along the internal arcuate fibres in the medulla. Only with the negative deflection of $\mathrm{P} 14$ (N15) is hemispheric asymmetry found, suggesting that this component arises in the medial lemniscus after the decussation of fibres. Other researchers in the field (e.g., Desmedt and Cheron, 1980; Jones, 1977; Anziska and Cracco, 1981) have argued on the basis of the P14 latency that it was generated in the medial lemniscus. We believe that our data allow a more precise localization of P14 to the internal arcuate fibres. Another possibility, however, is that the initial asymmetry reflects the greater lateralization of the medial lemniscus in the pons and that P14 is generated caudal to this in the medial lemniscus. Further studies in lesioned animals or in patients with medullary lesions will be required to arbitrate between these possibilities.

Maccabee et al. (1983) reported their N16, probably equivalent to our N15, was slightly lateralized but they suggested that it arose from the caudal thalamocortical radiation. We would argue, with others, that the PI6 and PI 7 arise from the thalamus and/or thalamocortical projections (Eisen, 1982; Abbruzzese et al., 1978), and hence the preceding negativity is generated prior to the thalamus. P16 and P17 were clearly asymmetrical in our subjects further suggesting that generator proximity may be the critical factor in these asymmetries. The thalamus is an essential relay in the somatosensory system but if it is a closed-field, as suggested by Arezzo et al. (1979), one could not record corresponding far-field components. However, Allison et al. (1983) have argued persuasively that the thalamus is in fact an 'open-closed' field, generating potentials that are complex and difficult to record, but that can be measured outside the thalamus. The use of a narrower bandpass than is usually employed for SEPs appears necessary to record these waves, in order to filter out the large slow waves which in standard recording paradigms would obscure the sinaller, relatively high-frequency subcortical components. The ease with which they can be 

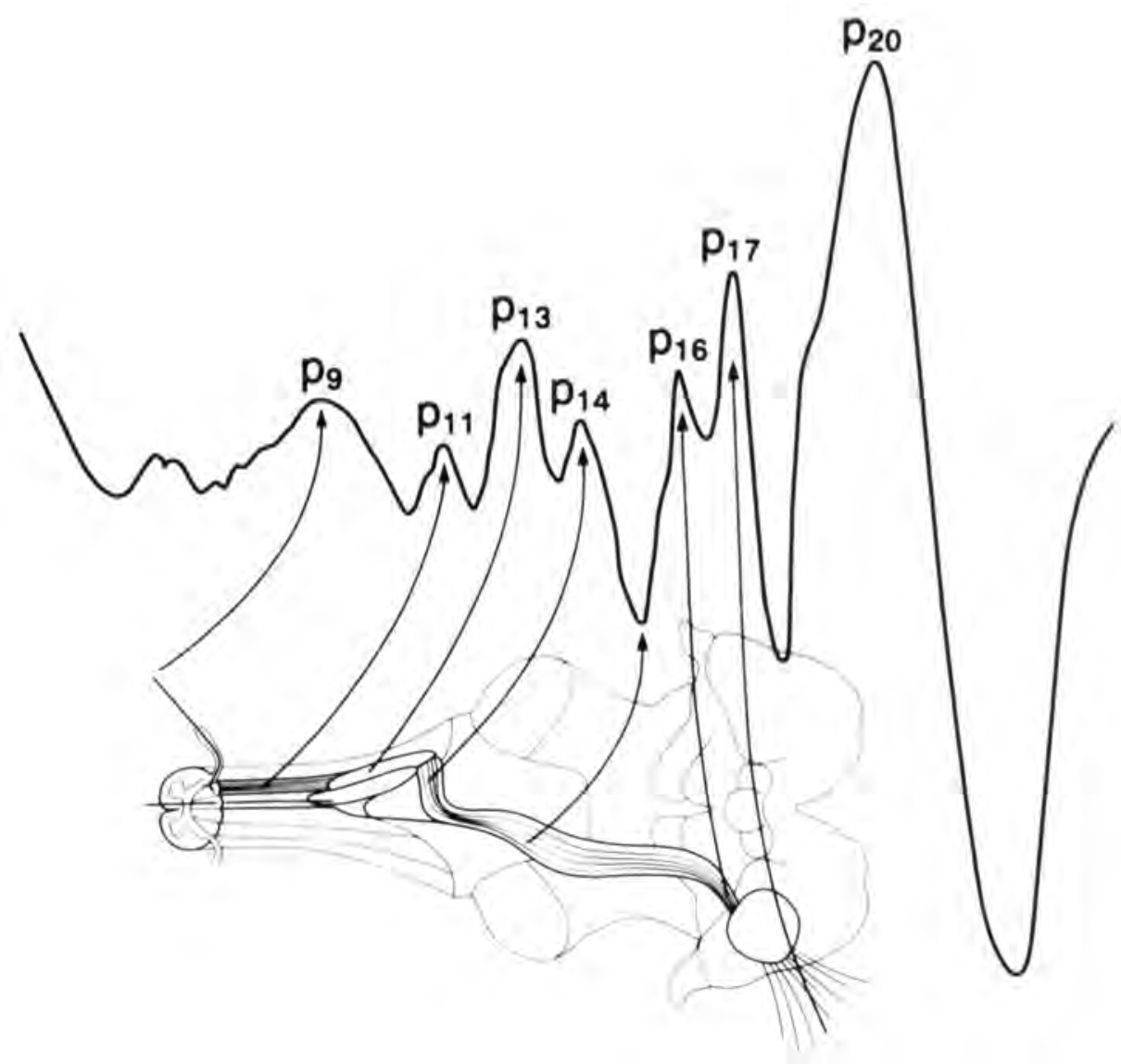

Figure 4 - The proposed generators of the component waves of the far-field SEP.P9 is from the brachial plexus, PII-reflects the afferent volley in the cervical dorsal column, Pl3 arises in the cuneate nucletss. P/4 from the internal arcuate fibres, the negative deflection following $P / 4$ from the medial lemniscus. PI6 reflects the afferent volley arriving at the thalamus and PI7 is from the thalamus or thalamocortical radiation. $P 20$ is the cortical response.

obtained with a $150-3000 \mathrm{~Hz}$, or a $300-3000 \mathrm{~Hz}$ bandpass (Maccabee et al., 1983), is reassuring and these far-field SEPs may well become as widely used as the ABR in investigating subcortical sites of damage. As the auditory and somatosensory pathways pass through different but adjacent structures, the use of both ABRs and far-field SEPs could yield a fuller and more detailed assessment of brainstem and thalamic function.

The N18 component discussed by Desmedt and Cheron (1981), which they also found to be lateralized, is likely the negative deflection following our P17. They did not record the series of earlier positive peaks, presumably because they used a bandpass of $.5-2500 \mathrm{~Hz}$. They argued, however, that N18 was a thalamic component. More recent data would now suggest that this is post-thalamic, probably in the rostral thalamocortical projection.

In contrast to some researchers (Eisen, 1982; Abbruzzese et al., 1978) we have attended primarily to the positive peaks in our data. The arguments in favour of this arise from the far-field recordings of the auditory brainstem pathway: positive peaks represent afferent ascending volleys (Picton et al., 1974; Jewett et al., 1970). When volume conducted potentials are being recorded, action potentials moving either towards or away from the active electrode will be measured as a positivity (Jewett, 1970). We recognize, however, that this is an arbitrary decision, and that negative peaks may well be as consistent in these recordings. The critical test for the method which best reflects specific sites in the pathway will be the assessment of clinical cases with known lesions.

Unlike Eisen (1982) and Abbruzzese et al. (1978) we were unable to record $\mathrm{P9}, \mathrm{P} 11$ and $\mathrm{PI} 3$ with an Fz reference. This accords with the findings of Maccabee et al., using their restricted bandpass and $\mathrm{Fz}$ reference, and suggests that recording of the more caudal far-field responses can be sensitive to such technical parameters as reference employed. Components P14, P16 and P17 were still clearly seen with the $\mathrm{Fz}$ reference in our study, but the amplitudes were diminished. This indicates that these components are detectable at both recording sites but that the signal is larger over the central than the frontal cortex. The non-cephalic components P9 and P1I and the first subcortical wave, P13, presumably projected equally to both cortical areas and therefore were cancelled out by the differential amplifiers. Since these waves are of small amplitude with any of the references used it is reasonable to employ the one that best enhances all the components.

The cortical and spinal SEPs are widely used as a clinical tool by neurologists, but the subcortical waves have not been reliable enough to be clinically applied. This study, in conjunction with other recent reports, suggests that this is no longer the case. Using a restricted bandpass and a non-cephalic reference, highly reproducible far-field SEPs that reflect the afferent volley from the brachial plexus to the thalamocortical projections can be obtained. Data from clinical populations with verifiable lesions in this pathway are needed to confirm the localization of the proposed generators of these far-field SEP components (e.g., Mauguiere et al., 1983; Nakanishi et al., 1983).

\section{ACKNOWLEDGEMENTS}

We wish to thank Drs. D. Hinton, W. Logan and H. Kwan for their helpful comments in preparing this manuscript. 


\section{REFERENCES}

Abbruzzese M, Favale E, Leandri M, Ratto S (1978) New subcortical components of the cerebral somatosensory evoked potential in man. Acta Neurol. Scand. 57: 325-332.

Allison L, Wood CC, McCarthy G (1983) The central nervous system. In "Psychophysiology: Systems, Processes and Applications", M. Coles, E. Donchin and S. Porges (eds.), Guilford Press, New York.

Anziska B, Cracco RQ (1981) Short latency SEPs to median nerve stimulation: comparison of recording methods and origin of components. Electroenceph. Clin. Neurophysiol. 52: 531-539.

Arezzo J, Legatt AD, Vaughan HG Jr (1979) Topography and intracranial sources of somatosensory evoked potentials in the monkey. 1 . Early components. Electroenceph. Clin. Neurophysiol. 46: 155-172.

Cracco RQ, Cracco JB (1972) Somatosensory evoked potential in man: far-field potentials. Electroenceph. Clin. Neurophysiol . 41: 460-466.

Desmedt JE. Cheron G (1980) Central somatosensory conduction in man: neural generators and interpeak latencies of the far-field components recorded from neck and right or left scalp and earlobes. Electroenceph. Clin. Neurophysiol. 50: 404-425.

Desmedt JE, Cheron $G$ (1981) Non-cephalic reference recording of early somatosensory potentials to finger stimulation in adult or aging normal man: differentiation of widespread N18 and contralateral N20 from the prelandic P22 and N30 components. Electroenceph. Clin. Neurophysiol. 52: 553-570.

Eisen A (1982) The somatosensory evoked potential. Can. J. Neurol. Sci. 9: 65-77.
Jewett D (1970) Volume-conducted potentials in response to auditory stimuli as detected by averaging in the cat. Electroenceph. Clin. Neurophysiol. 23: 609-618.

Jewett DL, Romano MM, Williston JJ (1970) Human auditory evoked potentials: Possible brain stem components detected on the scalp. Science 167: 1517-1518.

Jones SJ (1977) Short latency potentials recorded from the neck and scalp following median nerve stimulation in man. Electroenceph. Clin. Neurophysiol. 43: 853-863.

King DW, Green JB (1979) Short latency somatosensory evoked potentials in humans. Electroenceph. Clin. Neurophysiol. 46: 702-708.

Kritchevsky M, Wiederholt WC (1978) Short latency somatosensory evoked potentials. Arch. Neurol. 35: 706-711.

Maccabee PJ, Pinkhasov EI, Cracco RQ (1983) Short latency somatosensory evoked potentials to median nerve stimulation: effect of low frequency filter. Electroenceph. Clin. Neurophysiol. 55: 34-44.

Mauguiere F, Courjon J, Schott B (1983) Dissociation of early SEP components in unilateral traumatic section of the lower medulla. Ann. Neurol. 13: 309-313.

Nakanishi J, Lamaki M, Ozaki Y, Arasaki K (1983) Origins of short latency somatosensory evoked potentials to median nerve stimulations. Electroenceph. Clin. Neurophysiol. 56: 74-85.

Picton TW, Hillyard SA, Krausz HI, Galambos R (1974) Human auditory evoked potentials. I: Evaluation of components. Electroenceph. Clin. Neurophysiol. 36: 179-190. 